\title{
Effects of Chilling on Episcia and Dieffenbachia
}

\author{
Margaret J. McMahon, A.J. Pertuit, Jr., and James E. Arnold \\ Department of Horticulture, Clemson University, Clemson, SC 29634
}

Additional index words. carbon dioxide, chlorophyll, fluorescence, photosynthesis, transpiration

\begin{abstract}
Leaves of chilled 'Moss-Agate' Episcia (Mart.) plants exhibited direct chilling injury (i.e., watersoaked browning of leaf blade interveinal areas within $24 \mathrm{~h}$ of exposure to low temperature) immediately following exposure in darkness to $10 \mathrm{C}$ for 0.5 or $1.0 \mathrm{~h}$. Chlorophyll fluorescence peak : initial ratios and terminal : peak ratios of chilled Episcia were -reduced $20 \%$ and $25 \%$, respectively, $3 \mathrm{~h}$ after chilling, a result suggesting possible photosystem II damage. Total leaf chlorophyll content was reduced by $17 \%$ within $3 \mathrm{~h}$ of chilling and $\mathrm{CO}_{2}$ uptake also was reduced at this time. Leaves of chilled 'Rudolph Roehrs' Dieffenbachia maculata (Lodd.) (D. Roehrsii Hort.) plants expressed no visible injury within 24 $\mathrm{h}$ of $1.2 \mathrm{C}$ chilling in darkness for 36,48, or $60 \mathrm{~h}$, but $\mathrm{CO}_{2}$ uptake was reduced by $70 \%$ compared to the control $3 \mathrm{~h}$ after chilling. Visible injury began to appear $27 \mathrm{~h}$ after chilling, and the older leaf blades of all chilled plants exhibited a watersoaked appearance $75 \mathrm{~h}$ after chilling. Chlorophyll fluorescence peak: initial ratios of chilled Dieffenbachia did not vary, and terminal: peak ratios were not reduced until $147 \mathrm{~h}$ after chilling, when the injured tissue was extremely flaccid and translucent. Chilling reduced the chlorophyll content of Dieffenbachia by $10 \%$ in some plants $27 \mathrm{~h}$ after chilling and by $35 \%$. in all plants $75 \mathrm{~h}$ after chilling. Transpiration rate was reduced and stomata] diffusive resistance increased $27 \mathrm{~h}$ after chilling.
\end{abstract}

Marketed tropical and subtropical plants often are inadvertently exposed to chilling temperatures during production, transport, storage, and display. Exposure to these temperatures can induce chilling injury (CI), resulting in reduced yields or an unsightly, unsalable product.

All plant parts can be affected by chilling temperatures (Abbott and Massie, 1985, Bauer et al., 1985, Caldwell, 1987). Visible symptoms may include wilting, necrotic lesions, pitting, chlorosis, or a watersoaked appearance on portions of the damaged plant (Saltveit and Morris, 1990). Physiological symptoms, often the result of membrane destruction or dysfunction (Murphy and Wilson, 198 1; Yoshida, 1991), include altered photosynthetic and transpiration rates (Bauer et al., 1985). Symptoms appear immediately in some species, but develop over several days in others (Abbott and Massie, 1985; Bauer et al. 1985; Caldwell, 1987; Semeniuk et al., 1986).

Understanding some of the physiological effects of chilling on plants has helped develop methods of reducing CI. The process of hardening plants by gradually exposing them to lower temperatures is based on the premise that this procedure subtly alters the membrane to a form less affected by low temperatures (Murata. 1990; Wilson, 1987; Yakir et al., 1986). Applying an antitranspirant to the plants to prevent or reduce transpiration also protects plants from cold. These techniques, however, have not been successful with all plants. For example, Episcia reptans does not harden (Wilson, -1976). Also, antitranspirants did not reduce CI of Dieffenbachia maculata (Semeniuk et al., 1986). Qualifying and quantitating physiological changes resulting from CI could help detect plant injury before it becomes visually apparent and help develop techniques to ameliorate CI.

This study was undertaken to determine the effects of chilling on transpiration, $\mathrm{CO}$, uptake, chlorophyll content, and fluorescence of 'Moss-Agate' Episcia and 'Rudolph Roehrs' D. maculata (D. Roehrsii Hort.) and to determine if these measurements could be used as a rapid method for detecting CI in these species.

Received for publication 28 Dec. 1992. Accepted for publication 25 May 1993. Technical contribution no. 3009 of the South Carolina Agricultural Experiment Station. The use of trade names does not imply endorsement by the South Carolina Agricultural Experiment Station of products named, nor criticism of similar ones not mentioned. "The cost of publishing this paper was defrayed in part by the payment of page charges. Under postal regulations, this paper therefore must be hereby marked advertisement solely to indicate this fact.

\section{Materials and Methods}

Episcia. Rooted 'Moss-Agate' Episcia cuttings were planted during the week of 15 Oct. in 14-cm-diameter round, opaque, green plastic pots containing $450 \mathrm{~cm}^{3}$ of washed river sand. The plants were grown in a glasshouse shaded with white latex paint to provide a photosynthetic photon flux density of $25 \%$ of full sunlight $\left(\approx 1700 \mu \mathrm{mol} \cdot \mathrm{m}^{-2} \cdot \mathrm{s}^{-1}\right)$ during summer. The shade was not removed during winter, but weathered naturally to provide $\approx 50 \%$ full sunlight. A neutral-density gray polypropylene shade material was installed in the glasshouse to reduce solar radiation by an additional $5 \%$ to $10 \%$. The glasshouse was heated, but not cooled. Days ranged from $22 \mathrm{C}$ to $34 \mathrm{C}$; nights were maintained at $20 \pm 1 \mathrm{C}$. All plants were exposed to the same temperature regimes. Episcia were pruned to three or four nodes per stem 3 months before the experiment began. Plants were fertilized on alternate days with (mg.liter ${ }^{-1}$ ) 300N-132P-249K from Peter's (Fogelsville, Pa.) 2020-20. Water was applied as needed between fertilizations.

The design was a randomized complete-block split plot in time conducted on 17 and 24 Aug. Eighteen uniform, healthy appearing Episcia were selected on each date and six plants were assigned to each treatment. These plants had a full crown; stems extended outside the pot to the base of the pot. The treatments were exposure to $22 \pm 1 \mathrm{C}$ (control) or $10 \pm 0.5 \mathrm{C}$ for 0.5 or $1.0 \mathrm{~h}$ in a walk-in cooler (model 6706A008B; McCray Corp., Kendallville, Ind.) prechilled to 10C. Control plants were not placed in the cooler, rather in the room housing the cooler. Plants were placed in the cooler at 30-min intervals so that plants of all treatments could be removed at the same time. The room housing the cooler and the cooler were kept dark during the treatment period. Before the plants were chilled, iron-constantan thermocouples $(0.43 \times 0.71 \mathrm{~mm}$ in diameter) were inserted $0.64 \mathrm{~cm}$ into a petiole and $2.5 \mathrm{~cm}$ into the growing medium (as near the center of the pot as possible) of two plants of each treatment. An additional thermocouple recorded air temperature in the cooler. The thermocouples were attached to an analog digital converter (Analytical Development Co., London) connected to a Macintosh 512k computer (Apple Computer, Cupertino, Calif.). A software program was developed to monitor, display, and print plant, growing medium, and chamber temperatures. The number of available channels in the converter precluded monitoring temperatures in the control room. A high-low thermometer, however, was kept with the controls to establish the temperature range. 
Chlorophyll fluorescence, chlorophyll content, and CO, uptake were recorded $21 \mathrm{~h}$ before and $3 \mathrm{~h}$ after chilling. All measurements were taken between 2200 and $0100 \mathrm{HR}$ in the glasshouse under light (300 to $310 \mu \mathrm{mol} \cdot \mathrm{m}^{-2} \cdot \mathrm{s}^{-1}$ ) provided by a high-intensity discharge (HID) lamp (Lithonia Lighting Co., Crawfordsville, Ind.) using a 400-W multivapor bulb (General Electric Co., Cleveland). The light intensity chosen was the Episcia light saturation point that had been determined previously. Readings were taken at night to avoid high day temperatures and exposing analytical equipment to vehicle exhaust.

Chlorophyll fluorescence was evaluated according to Shaw et al. (1985) using a plant productivity fluorometer (model SF-20; Richard Brancker Research, Ottawa, Canada). The sensing probe was placed on the adaxial surface of a leaf resting on a flat black surface. The leaf and probe were covered to exclude light. After 3 min of dark acclimation, the monochromatic ( $670 \mathrm{~nm} \lambda$ max) lightemitting diode of the probe illuminated the leaf for $50 \mathrm{sec}(15.6$ $\left.\mu \mathrm{mol} \cdot \mathrm{m}^{-2} \cdot \mathrm{s}^{-1}\right)$. The initial fluorescence level, the peak, and the terminal value received by the fluorescence diode were recorded.

Five 3-mm-diameter disks from each leaf being evaluated were placed in $5 \mathrm{ml}$ of $\mathrm{N}, \mathrm{N}$-dimethylformamide and kept in darkness at $10 \mathrm{C}$ for 48 to $72 \mathrm{~h}$ to extract chlorophyll. Absorbance were measured spectrophotometrically (Spectronic 1001; Bausch and Lomb, Rochester, N.Y.) at 664 and $647 \mathrm{~nm}$. Total chlorophyll, chlorophyll a, and chlorophyll b were determined by the method developed by Moran and Porath (1980) and Moran (1982).

Net photosynthesis $\left(\mathrm{CO}_{2}\right.$ uptake) was measured with a portable infrared gas analyzer (IRGA) system (Analytical Development Co.) consisting of a Parkinson leaf chamber, leaf chamber analyzer, and air supply unit. The leaf chamber was clamped to a leaf until a steady state was achieved, then the $\mathrm{CO}_{2}$ differential (compared to a reference) in the chamber was recorded as ppm and converted to $\mathrm{mg} \cdot \mathrm{m}^{-2} \cdot \mathrm{s}^{-1}$.

Episcia $\mathrm{CO}_{2}$ uptake, chlorophyll content, and fluorescence were measured on the proximal end of fully expanded leaves in the top third of the plant, where preliminary tests indicated injury first occurred.

Two measurements of each criterion were taken on separate leaves of each Episcia. To sample chlorophyll content, tissues were removed, thus preventing repetitive sampling of exactly the same area; therefore, all measurements were done randomly. Once visible injury developed, measurements and sampling were confined to visibly injured areas.

Analysis of variance was performed on each measured variable to estimate experimental error variances. Analysis of variance revealed a chilling duration $\times$ day of evaluation interaction; hence, chilling durations were compared for each day of evaluation. Mean separation of chilling duration for each evaluation day was by Dunnett's test $(\alpha<0.05)$.

Dieffenbachia. Rooted 'Rudolph Roehrs' Diffenbachia cuttings were planted the week of 16 Sept. in 22.8-cm-diameter, round, opaque, green, plastic pots containing $1400 \mathrm{~cm}^{3}$ of washed river sand. Cultural practices were the same as for Episcia, except internal shade was not installed. The oldest cane of each plant was removed 4 months before the experiment began to reduce plant height and promote lateral cane development.

Dieffenbachia experiments were conducted on 13 and 27 Oct. Twenty-four uniform Dieffenbachia were selected for each date and divided into four treatment groups of six plants each. Dieffenbachia were exposed to $22 \pm 2 \mathrm{C}$ (control) or $1.2 \pm 0.2 \mathrm{C}$ for 24,36 , or $60 \mathrm{~h}$. These chilling treatments had produced moderate injury in preliminary experiments.

All plants to be chilled were placed in the cooler at staggered times, as for Episcia. The control remained at $22 \pm 2 \mathrm{C}$ in the room housing the cooler until chilling treatments were completed. The room and the cooler were kept dark during the treatment period and thermocouples were placed as previously described for Episcia.

Dieffenbachia transpiration rate, diffusive resistance, chlorophyll fluorescence, chlorophyll content, and $\mathrm{CO}_{2}$ uptake were recorded $21 \mathrm{~h}$ before and 3,27, 75, and $147 \mathrm{~h}$ after chilling. Attempts to collect data during the night failed when the Dieffenbachia did not evolve measurable oxygen after $1 \mathrm{~h}$ of exposure to artificial light. Cool fall days allowed us to collect data between 1000 and $1400 \mathrm{HR}$, when vehicular exhaust was not a problem. Natural light (in the glasshouse) was augmented with the previously described HID to provide 390 to $400 \mu \mathrm{mol} \cdot \mathrm{m}^{-2} \cdot \mathrm{s}^{-1}$; this was the previously determined light saturation point for Dieffenbachia.

Chlorophyll fluorescence, chlorophyll content, and $\mathrm{CO}_{2}$ uptake were measured with the same equipment as for Episcia. Transpiration and diffusive resistance were measured with with a steadystate porometer (model 1600; LI-COR, Lincoln, Neb.) clamped onto a leaf until a steady state was obtained.

Preliminary tests indicated that the initial injury site was on fully expanded leaves in the lower two-thirds of the plant. Measurements were taken in the middle third of the leaf blade along, or adjacent to, its margin. Chlorophyll content and fluorescence were measured along the margin, where preliminary tests indicated a higher chlorophyll content and less chlorophyll variation than in the interior of the blade. Because the designs of the porometer and IRGA chambers precluded their attachment at the exact margin, measurements were made slightly inside the dark green margin. Stomate counts were similar for the leaf margin and interior.

Two measurements of each criterion were taken on separate leaves of each Dieffenbachia. Chlorophyll content was sampled as for Episcia. Once visible injury developed, measurements and sampling were confined to the visibly injured area.

The design, analysis of variation, and mean separation were the same as for Episcia.

\section{Results}

Episcia. Temperatures in chilled plant petioles reached 10C within $15 \mathrm{~min}$ after chilling began and remained there (within $0.5 \mathrm{C}$ ) during treatment. Medium temperatures fell to $14 \mathrm{C}$ during $0.5 \mathrm{~h}$ chilling and to $13 \mathrm{C}$ during $1.0 \mathrm{~h}$ of chilling.

CI in both Episcia treatments was apparent when the plants were removed from the cooler. Damage was more severe as exposure time increased. The common visible injury was a watersoaked browning of leaf blade interveinal areas, with younger, almost fully expanded leaves most severely injured. The amount of injured area did not increase with time. The injured portion of the leaf eventually dessicated but, unless severely damaged, the injured leaves survived and the plant continued growing.

Table 1. Effects of three chilling durations $(0.0,0.5$, and $1.0 \mathrm{~h})$ at $10 \mathrm{C}$ on fluorescence ratios (peak: initial), $\mathrm{CO}_{2}$ uptake, and leaf chlorophyll content of 'Moss-Agate' Episcia. Measurements were taken $3 \mathrm{~h}$ after chilling ended.

\begin{tabular}{lccc}
\hline \hline $\begin{array}{l}\text { Chilling } \\
(\mathrm{h})\end{array}$ & $\begin{array}{c}\text { Fluorescence } \\
\text { ratio }\end{array}$ & $\begin{array}{c}\mathrm{CO}_{2} \text { uptake } \\
\left(\mu \mathrm{g} \cdot \mathrm{c} \mathrm{m}^{-2} \cdot \mathrm{s}^{-1}\right)\end{array}$ & $\begin{array}{c}\text { Chlorophyll } \\
\left(\mu \mathrm{g} \cdot \mathrm{cm}^{-2}\right)\end{array}$ \\
\hline 0.0 & $1.4 \mathrm{a}^{\mathrm{z}}$ & $0.7 \mathrm{a}$ & $40 \mathrm{a}$ \\
0.5 & $1.1 \mathrm{~b}$ & $-0.2 \mathrm{~b}$ & $33 \mathrm{~b}$ \\
1.0 & $1.1 \mathrm{~b}$ & $-0.2 \mathrm{~b}$ & $33 \mathrm{~b}$ \\
\hline
\end{tabular}

${ }^{\bar{z}}$ Mean separation within columns by Dunnett's test, $P \leq 0.05$. 
The chlorophyll fluorescence peak : initial ratio decreased $\approx 20 \%$ from the control within $3 \mathrm{~h}$ after chilling ended (Table.1). The terminal: peak ratio also was reduced by this time $(\approx 25 \%$ from the control; data not shown). After $3 \mathrm{~h}$, there was $\mathrm{CO}_{2}$ evolution rather than a net uptake for treated plants (Table 1). Total chlorophyll content of both chilled treatments had decreased $\approx 20 \%$ from the control within $3 \mathrm{~h}$ (Table 1).

Dieffenbachia. Temperatures of chilled Dieffenbachia petioles reached $1.3 \pm 0.5 \mathrm{C}$ within $25 \mathrm{~min}$ of chilling and remained there during treatment. Growing-medium temperatures reached $1.2 \pm$ $0.5 \mathrm{C}$ within $4 \mathrm{~h}$ and remained constant.

Dieffenbachia had no visible injury when chilling ended; however, visible injury had developed in the leaf blades at the basal two-thirds of some chilled plants $27 \mathrm{~h}$ after chilling ended. The damage first appeared on the underside of the leaf blade as a watersoaked area at or near the leaf margin. Injury was visible in all chilled plants after $75 \mathrm{~h}$ and continued to develop. Most damaged leaves became brown, wilted, then died. The upper third of the Dieffenbachia was not visibly affected and growth continued. Lateral shoots developed normally from lateral nodes where the damaged petioles were attached.

Chilled Dieffenbachia fluorescence peak: initial ratios did not vary from the control during the evaluation period (data not shown). Net $\mathrm{CO}_{2}$ uptake was reduced to near zero $3 \mathrm{~h}$ after treatment in all chilled Dieffenbachia, and it remained low during the evaluation period (Fig. 1).

Dieffenbachia total chlorophyll concentration was reduced by $\approx 35 \%$ in all chilled plants $75 \mathrm{~h}$ and $\approx 65 \% 147 \mathrm{~h}$ after chilling ended (Fig. 2).

Chilled Dieffenbachia had a much reduced transpiration rate ( $\approx 75 \%$ of the control) $27 \mathrm{~h}$ after chilling ended, and transpiration was barely detectable for the rest of the experiment (Fig. 3). Diffusive resistance of all chilled Dieffenbachia had increased about threefold $27 \mathrm{~h}$ after exposure compared to the control and remained much higher than that of the control (Fig. 4) until the experiment ended.

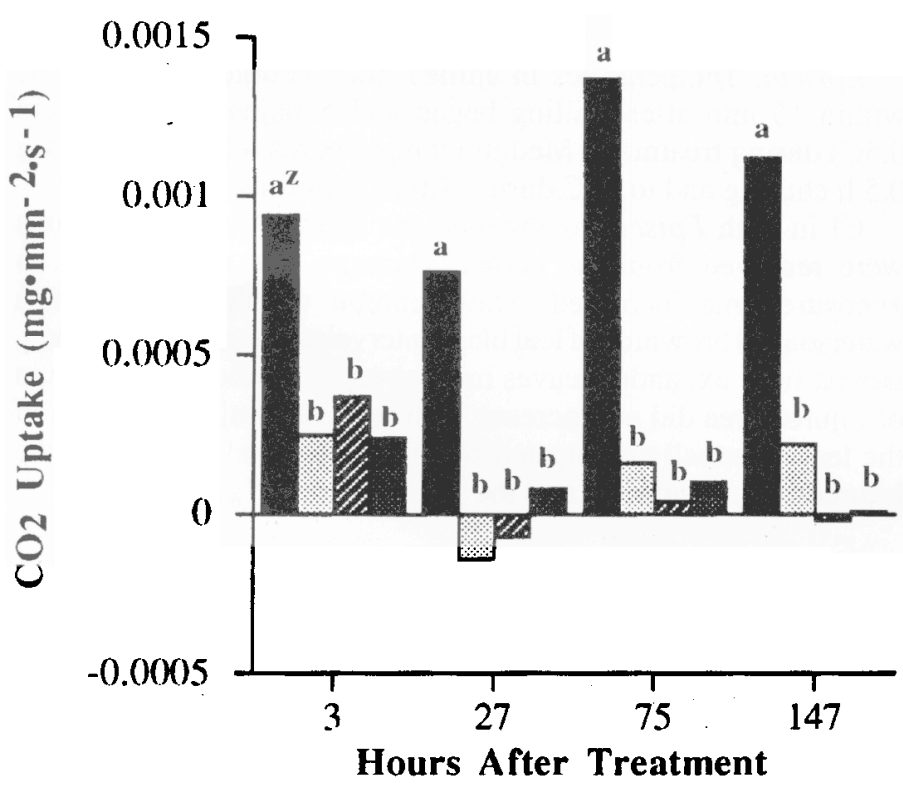

Fig. 1. Effect of 0 (shaded bar), 36 (unshaded bar with black dots), 48 (shaded bar with diagonal white lines), and 60 (shaded bar with white dots) $\mathrm{h}$ of chilling in darkness at $1.2 \mathrm{C}$ on $\mathrm{CO}_{2}$ uptake of 'Rudolph Roehrs' Dieffenbachia maculata 3, 27,75 , and $147 \mathrm{~h}$ after chilling ended. 'Mean separation within hours by Dunnett's test, $P \leq 0.05$. Same letters indicate no significant difference.

\section{Discussion}

Episcia. Visible injury provided an easy and rapid method of detecting CI. Reduced $\mathrm{CO}_{2}$ uptake and the loss of leaf chlorophyll within hours after chilling indicates that the photosynthetic or carbon fixation system or both had been damaged. The normal fluorescence pattern induced by illumination following a dark period is an initial fluorescence level, followed in less than a

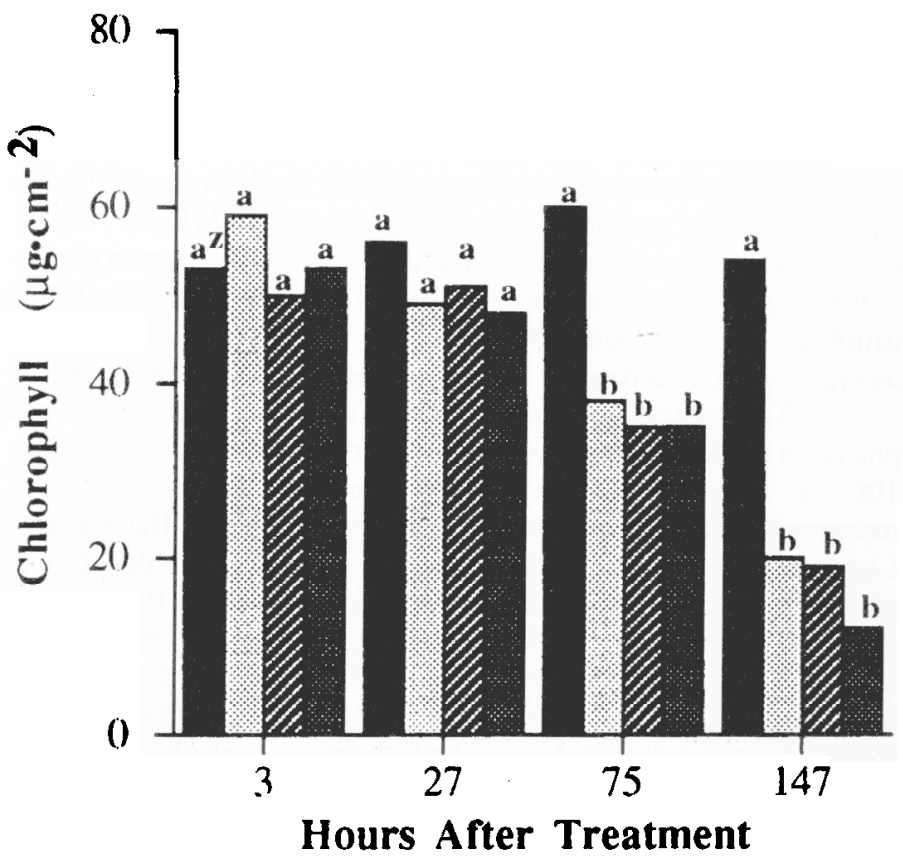

Fig. 2. Effect of 0 (shaded bar), 36 (unshaded bar with black dots), 48 (shaded bar with diagonal white lines), and 60 (shaded bar with white dots) $\mathrm{h}$ of chilling in darkness at $1.2 \mathrm{C}$ on total chlorophyll of 'Rudolph Roehra' Dieffenbachia maculata $3,27,75$, and $147 \mathrm{~h}$ after chilling ended. 'Mean separation within hours by Dunnett's test, $P \leq 0.05$. Same letters indicate no significant difference.

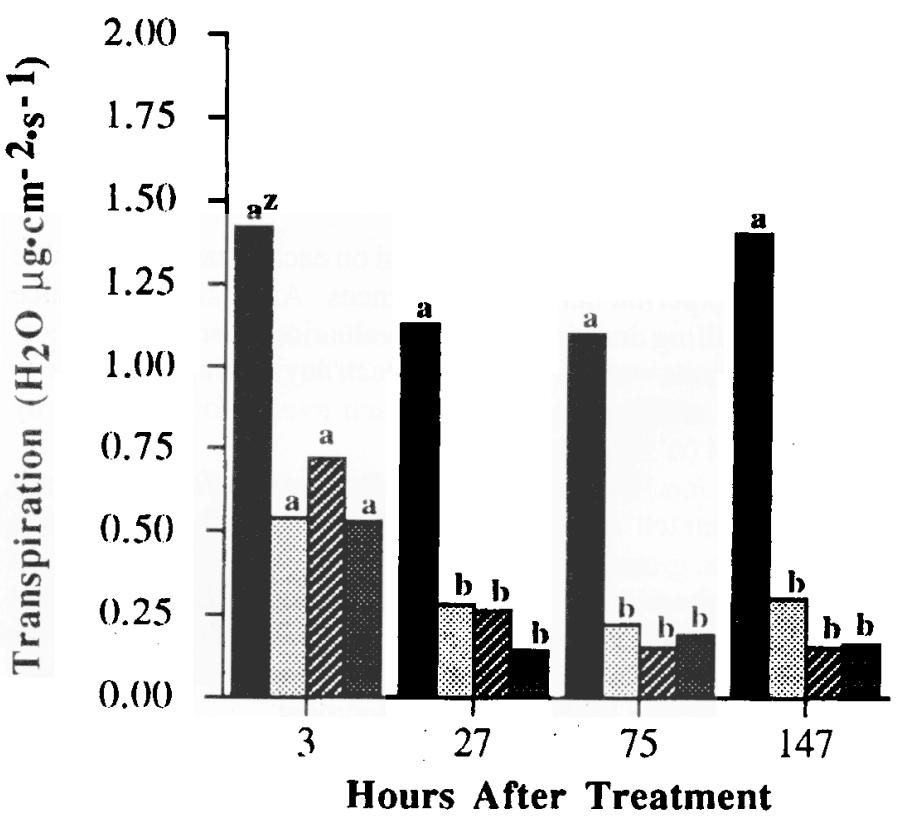

Fig. 3. Effect of 0 (shaded bar), 36 (unshaded bar with black dots), 48 (shaded bar with diagonal white lines), and 60 (shaded bar with white dots) h of chilling in darkness at $1.2 \mathrm{C}$ on transpiration of 'Rudolph Roehrs' Dieffenbachia maculata $3,27,75$, and $147 \mathrm{~h}$ after chilling ended. 'Mean separation within hours by Dunnett's test, $P \leq 0.05$. Same letters indicate no significant difference. 


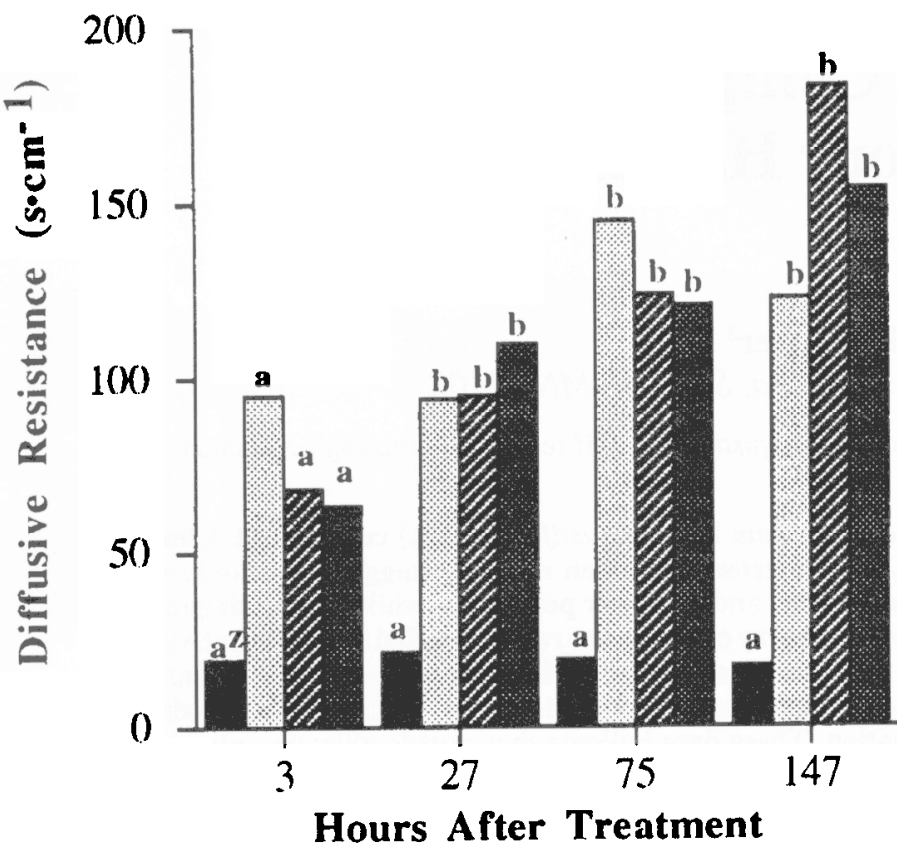

Fig. 4. Effect of 0 (shaded bar), 36 (unshaded bar with black dots), 48 (shaded bar with diagonal white lines), and 60 (shaded bar with white dots) h of chilling in darkness at $1.2 \mathrm{C}$ on diffusive resistance of 'Rudolph Rochrs' Dieffenbachia maculata 3,27,75, and $147 \mathrm{~h}$ after chilling ended. 'Mean separation within hours by Dunnett's test, $P \leq 0.05$. Same letters indicate no significant difference.

nanosecond by a fluorescence peak, then a decline to near initial levels (Kautsky, 1931). In chilled Episcia, the reduced fluorescence peak suggests that photosystem (PS) II was damaged and unable to hydrolyze water. Additionally, no decline from the peak indicates that the oxidation-reduction chain linking PS II to PS I is inhibited or that PSI is unable to accept electrons (Conroy et al., 1986; Ogren and Oquist, 1985; Shaw et al., 1985).

Understanding the cause of reduced $\mathrm{CO}_{2}$ uptake and the loss of the fluorescence peak may provide a means of ameliorating injury. The survivability of parts of the leaf, especially the vascular system, indicates that physiological differences exist among leaf tissues; understanding these differences might also lead to methods of preventing or reducing CI.

Dieffenbachia. Reduced $\mathrm{CO}_{2}$ uptake within $3 \mathrm{~h}$ after chilling ended probably was not the result of chlorophyll loss. Chlorophyll content of chilled Dieffenbachia did not decrease until 75 h after treatment, a result indicating that chlorophyll was probably available for photosynthesis during the earlier period. The increase of diffusive resistance $3 \mathrm{~h}$ after chilling for some chilled Dieffenbachia and $27 \mathrm{~h}$ after chilling for the remaining chilled plants could partially account for the reduced $\mathrm{CO}_{2}$ uptake. Because visible injury coincided with the loss of chlorophyll and neither was immediately apparent, chlorophyll loss was apparently the result of gradual cell death.

Dieffenbachia fluorescence was not useful for determining if the photosystem was disrupted. The lack of differences in fluorescence peak : initial ratios could indicate that the photosystem was not damaged. More likely, because the ratios were already low (1.1:1.0, detailed data not shown) for nonchilled plants, the differences were so slight that they were not detectable. The normal low ratios must be the result of Dieffenbachia physiology. The thylakoid arrangement of some shade plants indicates that the linkage between PS II and PS I is different between shade and sun plants. The difference in linkage may affect fluorescence patterns (Anderson, 1982).
Increased diffusive resistance and decreased transpiration in chilled plants indicates that stomata were not locked open, although it is possible that water loss though transpiration was greater than could be replaced by uptake from chilled roots. However, noninjured leaves never wilted and injured leaves did not wilt until $75 \mathrm{~h}$ after chilling, a result indicating that transpiration was not excessive within the first 2 or 3 days after chilling,

The reduced $\mathrm{CO}_{2}$ uptake after chilling is a means of detecting CI before it is visible. Variability in transpiration and diffusive resistance decreases their effectiveness as $\mathrm{CI}$ indicators.

At this time, the specific mechanism of CI remains unknown in Dieffenbachia. However, further investigation of the physiology of immature Dieffenbachia leaves may provide a means of ameliorating CI, as these leaves apparently were resistant to our chilling treatments.

\section{Literature Cited}

Abbott, J.A. and D.R. Massie. 1985. Delayed light emission for early detection of chilling injury in cucumber and bell pepper fruit. J. Amer. Soc. Hort. Sci. 110:42-47.

Anderson, J.M. 1982. The significance of chlorophyll stacking in bcontaining chloroplasts. Photobiochem. Photobiophys. 3 :225-241.

Bauer, H., R. Wierer, W.H. Hathaway, and W. Larcher. 1985. Photosynthesis of Coffea arabica after chilling. Physiol. Plant. 64:449-454.

Caldwell, C.R. 1987. Temperature-induced protein conformations changes in barley root plasma membrane-enriched microsomes. Plant Physiol. 84:926-929.

Conroy, J.P., R.M. Smillie, M. Kuppers, D.I. Bevege, and E.W. Barlow. 1986. Chlorophyll a fluorescence and photosynthetic growth responses of Pinus radiata to phosphorus deficiency, drought stress and high $\mathrm{CO}_{2}$. Plant Physiol. 81:423-429.

Kautsky, H. and A. Hirsch. 1931. Neue Versuche zur Kohlensäureassimilation. Naturwissenschaften 19:964.

Moran, R. 1982. Formulae for determination of chlorophyllous pigments extracted with $N, N$-dimethylformamide. Plant Physiol. 69:1376-1381.

Moran, R. and D. Porath. 1980. Chlorophyll determinations in intact tissues using $N, N$-dimethylfortnatnide. Plant. Physiol. 65:478-479.

Murata, T. 1990. Lipids in relation to chilling sensitivity of plants, p. 201210. In C.Y. Wang (cd.). Chilling injury of horticultural crops. CRC Press, Boca Raton, Fla.

Murphy, C. and J.W. Wilson. 1981. Ultrastructural features of chilling injury in Episcia reptans. Plant Cell Environ. 4:261-265.

Ogren, E. and G. Oquist. 1985. Effects of drought on photosynthesis, chlorophyll fluorescence and photoinhibition in intact willow branches. Planta 166:380-388.

Saltveit, Jr., M.E. and L.L. Morris. 1990. Overview of chilling injury of horticultural crops, p. 3-16. In: C.Y. Wang (cd.). Chilling injury of horticultural crops. CRC Press, Boca Raton, Fla.

Semeniuk, P., H.E. Moline, and J.A. Abbott. 1986. A comparison of ABA and an antitranspirant on chilling injury of coleus, cucumbers and dieffenbachia. J. Amer. Soc. Hort. Sci. 111:866-868.

Shaw D.R., T.F. Peeper, and D.L. Nofziger. 1985. Comparison of chlorophyll fluorescence and fresh weight as herbicide bioassay techniques. Weed Sci. 33:29-33.

Wilson, J.M. 1976. The mechanism of chill- and drought-hardening of Phaseolus vulgaris leaves. New Phytologist 76:257-270.

Wilson, J.M. 1987. Chilling injury in plants, p. 271-292. In: B.W.W. Grout and G.J. Morns (eds.). The effects of low temperatures on biological systems. Edward Arnold Publishers, London.

Yakir, D., J. Rudich, and B.A. Bravdo. 1986. Adaptation to chilling: Photosynthetic characteristics of the cultivated tomato and a high altitude wild species. Plant Cell Environ. 9:477-484.

Yoshida, S. and C. Matsuura-Endo. 1991. Comparison of temperature dependency of tonoplast translocation between plants sensitive and insensitive to chilling. Plant Physiol. 95:504-508. 